\title{
Perioperative Indicators of Stress Response and Postoperative Inflammatory Complications in Patients Undergoing Off-Pump Coronary Artery Bypass Surgery A Prospective Observational Study
}

\author{
Suk-Won Song, MD, PhD; Gijong Yi, MD; Sak Lee, MD*; Young-Nam Youn, MD*; \\ Soon-Young Sul, RN*; Kyung-Jong Yoo, MD, PhD*
}

\begin{abstract}
Background Little has been published regarding the association between perioperative stress response and clinical outcomes after off-pump coronary artery bypass surgery (OPCAB). The role of perioperative stress response in postoperative inflammatory complications (PIC) in patients undergoing OPCAB was assessed.

Methods and Results The study cohort consisted of 100 patients who underwent elective OPCAB over a 5-month period. Anesthetic management was standardized and blood samples were collected before surgery, immediately after surgery, and 1,2,3, and 7 days after surgery. Leukocyte, neutrophil, platelet, erythrocyte sedimentation rate, C-reactive protein, fibrinogen, cortisol, D-dimer, and fibrin degradation product were measured at each time point, and the association of each parameter with PIC was assessed. PIC included postoperative pulmonary complications, atrial fibrillation, and wound infections. PIC occurred in 30 patients at the median third postoperative day. Multivariate analysis showed preoperative cortisol $(\mathrm{p}=0.024)$ and cortisol on the first postoperative day $(\mathrm{p}=0.001)$ were significantly associated with PIC. Intraoperative cortisol release was correlated with intraoperative hemodynamic changes, including pulmonary artery pressure, central venous pressure, and cardiac index.

Conclusions Patients with PIC after OPCAB have significantly increased preoperative cortisol and cortisol on the first postoperative day. Intraoperative cortisol release was significantly correlated with hemodynamic changes. The neurohormonal environment and inflammatory response during and after beating-heart surgery should be further explored. (Circ J 2008; 72: 1966-1974)
\end{abstract}

Key Words: Cortisol; Off-pump coronary artery bypass surgery

$\mathbf{P}$ atients undergoing cardiac surgery under cardiopulmonary bypass (CPB) frequently experience systemic inflammatory reactions that could result in increased postoperative morbidity and prolonged hospital stay! Important features of these inflammatory reactions include the activation of complement ${ }^{2}$ and leukocytes, the release of proinflammatory cytokines, 3 alterations in nitric oxide metabolism, 4 and increased production of oxygen free radicals, which in some cases leads to oxidant stress injury, 5 Among the strategies used to reduce the inflammatory reactions induced by $\mathrm{CPB}$ and its consequences are treatment with steroids? aprotinin, 8 ,9 heparin-coated CPB circuits, ${ }^{10}$ and hemofiltration ${ }^{11}$

The omission of CPB itself might be a more radical and effective way of counteracting the effects of these inflamma-

(Received March 19, 2008; revised manuscript received June 10, 2008; accepted July 15, 2008; released online October 21, 2008)

Department of Thoracic and Cardiovascular Surgery, Yongdong Severance Hospital, *Department of Thoracic and Cardiovascular Surgery, Yonsei Cardiovascular Hospital, Yonsei University Health System, Seoul, Republic of Korea

Mailing address: Kyung-Jong Yoo, MD, PhD, Yonsei Cardiovascular Hospital, Yonsei University College of Medicine, 134 Shinchondong, Seodaemun-ku, Seoul 120-752, Republic of Korea. E-mail: kjy@ yuhs.ac

All rights are reserved to the Japanese Circulation Society. For permissions, please e-mail: cj@j-circ.or.jp tory reactions and oxidative stress. For example, the rate of postoperative morbidity is reduced in patients undergoing cardiac operations without $\mathrm{CPB}, 2$ and inflammatory reactions in patients undergoing bypass graft operations were reduced when CPB was not used 13,14 Although avoidance of CPB should provide a more physiological milieu and reduce the perioperative stress response, with preservation of perioperative organ function, little has been published regarding the association of perioperative stress response and clinical outcomes after off-pump coronary artery bypass surgery $(\mathrm{OPCAB})$. We therefore assessed the role of perioperative systemic inflammation and stress response on postoperative inflammatory complications (PIC) in patients undergoing OPCAB.

\section{Methods}

The patient cohort consisted of all patients scheduled for isolated primary OPCAB between May and September 2007. Patients undergoing emergency surgery and those with a history of previous cardiac surgery, preoperative exposure to warfarin sodium, platelet glycoprotein IIb/IIIa inhibitors, or thrombolytics were excluded. The 100 included patients were divided into 2 groups: the PIC group ( $\mathrm{n}=30,30 \%)$, consisting of patients with evidence of PIC; and the non-PIC group $(n=70)$, consisting of patients with no evidence of PIC.

The study protocol was approved by our institutional re- 
view board (Yonsei IRB No.4-2007-0135), and written informed consent was obtained from each patient.

\section{Definitions of PIC}

PIC included the following 3 conditions: postoperative pulmonary complications; postoperative atrial fibrillation; and wound infections.

\section{Postoperative Pulmonary Complications}

Acute respiratory distress syndrome was defined as: (1) acute onset with a $\mathrm{PaO}_{2} /$ fraction of inspired oxygen of $200 \mathrm{mmHg}$ or less. (2) Bilateral infiltrates: the infiltrates might be patchy, diffuse, homogeneous, or asymmetrical, and should be consistent with pulmonary edema or fibrotic changes associated with fibroproliferation. Opacity as a result of pleural effusions or atelectasis should not be considered. Unilateral infiltrate was included for pneumonectomy patients. (3) No evidence of left atrial hypertension. If measured, a pulmonary artery wedge pressure must be $18 \mathrm{mmHg}$ or less. (4) The 3 previously cited criteria must occur together within a 24-h interval 15,16

Acute lung injury was defined as: (1) acute onset with a $\mathrm{PaO}_{2} /$ fraction of inspired oxygen of $300 \mathrm{mmHg}$ or less; (2) bilateral infiltrates; and (3) no evidence of left atrial hypertension. If measured, a pulmonary artery wedge pressure of $18 \mathrm{mmHg}$ or less.

For pulmonary infection, (1) pneumonia was diagnosed on the basis of a compatible chest radiograph and purulent sputum with Gram's stain and sputum culture documenting the presence of microorganisms; (2) aspiration pneumonitis was defined as either the presence of bilious secretion or particulate matter in the tracheobronchial tree, or, in patients who did not have their tracheobronchial airways directly examined after regurgitation, a postoperative chest radiograph with infiltrates not identified on a preoperative radiograph; sputum retention was defined as inability to adequately clear the tracheobroncheal secretions with standard physiotherapy, which was coincided with lobar or whole-lung atelectasis based on chest radiography requiring aspiration bronchoscopy. The diagnosis was essentially clinical, characterized by evidence of respiratory distress with rapid, shallow, and bubbly respirations. Bronchospasm was defined as a condition of respiratory dysfunction characterized by evidence of severe wheezing or a prolonged expiratory phase requiring aminophylline loading, aerosolized bronchodilator, $\beta$ agonist, and steroid therapy.

Prolonged chest tube drainage was defined as drainage of pleural fluid equal or more than 2 weeks.

\section{Postoperative Atrial Fibrillation}

Postoperative atrial fibrillation was defined as an irregularly irregular supraventricular rhythm present in the absence of $\mathrm{P}$ waves that required treatment and that was typically sustained for more than $15 \mathrm{~min}$. Arrhythmia data were collected and recorded for the first 7 postoperative days. Patients were continuously monitored in the cardiac surgery intensive care unit (ICU) with arterial, central venous, and pulmonary artery pressure monitoring and thermodilution cardiac output determination. Cardiac rhythm was continuously monitored in the ICU with bedside monitors and daily monitored with 12-lead electrocardiogram on the general ward until discharge.

\section{Wound Infections}

Wound infections were categorized into 3 types: impaired wound healing, superficial wound infections, and deep wound infections. Impaired wound healing was defined as wound erythema and a purulent discharge necessitating additional antibiotic agents and/or hospitalization. Diagnoses of superficial and deep infections were based on the wound swab culture results. The time interval for assessment of wound infection was the in-hospital period.

\section{Anesthesia}

All patients were managed according to the same anesthetic management protocol. Upon arrival in the operating room, each patient was linked to standard monitoring devices, including a pulmonary arterial catheter (Swan-Ganz $\mathrm{CCOmbo} \mathrm{CCO} / \mathrm{SvO}_{2}$; Edwards Lifesciences, Irvine, $\mathrm{CA}$, USA), before induction of anesthesia. After induction of anesthesia, a transesophageal echocardiography probe was inserted to detect newly developing segmental wall motion abnormalities. Intravascular volume replacement was managed with crystalloid and colloid solutions to maintain the pulmonary capillary wedge pressure between 8 and $16 \mathrm{mmHg}$, depending on baseline values. Central temperature, as measured by pulmonary arterial catheter, was maintained between $36^{\circ} \mathrm{C}$ and $37^{\circ} \mathrm{C}$ with a warm mattress, forced warm air blanket, and fluid warmer, as necessary.

\section{Surgical Procedure}

All surgical procedures were performed by 1 surgeon (K.J.Y) through a median sternotomy, and the heart was displaced with a posterior pericardial stitch and tissue stabilizer. The grafting sequence consisted of the left anterior descending coronary artery first, followed by the left circumflex coronary artery and the right coronary artery. During the period of heart displacement, mean systemic arterial pressure was maintained above 60 to $70 \mathrm{mmHg}$ with a $10^{\circ}$ to $20^{\circ}$ Trendelenburg position and/or norepinephrine infusion. Cell salvage was always used during surgery, and salvaged blood was reinfused before the end of the operation. Allogenic packed red blood cells were transfused when hemoglobin concentration fell below $8 \mathrm{mg} / \mathrm{dl}$. After surgery, all patients were transferred to the ICU.

\section{Intraoperative Hemodynamic Changes}

Hemodynamic variables, including heart rate, mean arterial pressure, central venous pressure, mean pulmonary arterial pressure, cardiac index, and mixed venous oxygen saturation, were recorded $15 \mathrm{~min}$ after induction of anesthesia (baseline), $10 \mathrm{~min}$ after stabilizer application for left circumflex coronary artery grafting, and $15 \mathrm{~min}$ after sternum closure. The volume of infused fluids and urine output during surgery and for $12 \mathrm{~h}$ in the ICU were recorded, as was the amount of norepinephrine infused during the operation.

\section{Blood Sampling}

Arterial blood samples were collected before induction of anesthesia, at the end of surgery, and 1,2,3, and 7 days after surgery. Blood samples were collected into sterile tubes containing trisodium citrate anticoagulant or potassium EDTA.

\section{Assessment of Inflammatory Reactions}

Inflammatory response was assessed by measuring blood leukocyte and neutrophil count, erythrocyte sedimentation rate (ESR), C-reactive protein (CRP), fibrinogen, and cortisol. Fibrinogen concentrations were determined using the thrombin clotting method, with a normal range of 200 to $400 \mathrm{mg} / \mathrm{dl}$. 
Table 1 Preoperative Patient Characteristics

\begin{tabular}{|c|c|c|c|}
\hline & $\begin{array}{c}\text { PIC group }(n=30) \\
\text { No. }(\%)\end{array}$ & $\begin{array}{c}\text { Non-PIC group }(n=70) \\
\text { No. }(\%)\end{array}$ & $p$ value \\
\hline Age (years) & $66.8 \pm 7.2$ & $62.4 \pm 10.5$ & 0.038 \\
\hline Female & $10(33.3)$ & $20(28.6)$ & 0.812 \\
\hline$B M I\left(\mathrm{~kg} / \mathrm{m}^{2}\right)$ & $24.4 \pm 3.5$ & $24.1 \pm 2.8$ & 0.804 \\
\hline Obesity & $13(43.3)$ & $25(35.7)$ & 0.506 \\
\hline Diabetes & $11(36.7)$ & $24(34.3)$ & 1.000 \\
\hline$I D D M$ & $1(3.3)$ & $4(5.7)$ & \\
\hline NIDDM & $10(33.3)$ & $19(27.1)$ & \\
\hline Hypertension & $21(70.0)$ & $48(68.6)$ & 1.000 \\
\hline Dyslipidemia & $13(43.3)$ & $34(48.6)$ & 0.667 \\
\hline$s / p$ PTCA $c$ stent & $7(23.3)$ & $6(8.6)$ & 0.056 \\
\hline$A R F$ & $1(3.3)$ & $0(0)$ & 0.300 \\
\hline$C R F$ & $0(0)$ & $7(10.0)$ & 0.099 \\
\hline ESRD on dialysis & $0(0)$ & $3(4.3)$ & 0.552 \\
\hline Renal transplantation & $0(0)$ & $2(2.9)$ & 0.576 \\
\hline$P A O D$ & $3(10.0)$ & $16(22.9)$ & 0.170 \\
\hline Carotid stenosis & $3(10.0)$ & $3(4.3)$ & 0.361 \\
\hline$C V A$ & $4(13.3)$ & $4(5.7)$ & 0.236 \\
\hline Smoking & $14(46.7)$ & $33(47.1)$ & 1.000 \\
\hline Unstable angina & $8(27.6)$ & $21(32.3)$ & 0.810 \\
\hline$A M I$ & $6(20.0)$ & $6(8.6)$ & 0.245 \\
\hline Arrhythmia & $2(6.7)$ & $5(7.1)$ & 0.839 \\
\hline 3-vessel disease & $27(90.0)$ & $53(76.8)$ & 0.168 \\
\hline Left main disease & $5(16.7)$ & $17(24.3)$ & 0.445 \\
\hline$E F(\%)$ & $58.9 \pm 11.1$ & $54.5 \pm 13.5$ & 0.136 \\
\hline NYHA class & & & 0.544 \\
\hline 1 & $1(3.3)$ & $6(8.6)$ & \\
\hline 2 & $14(46.7)$ & $36(51.4)$ & \\
\hline 3 & $10(33.3)$ & $22(31.4)$ & \\
\hline 4 & $5(16.7)$ & $6(8.6)$ & \\
\hline Standard Euroscore & $3.7 \pm 3.6$ & $2.7 \pm 1.9$ & 0.156 \\
\hline Logistic Euroscore & $5.6 \pm 12.2$ & $2.5 \pm 2.0$ & 0.187 \\
\hline
\end{tabular}

PIC, postoperative inflammatory complications; BMI, body mass index; IDDM, insulin dependent diabetes mellitus; NIDDM, nonIDDM; PTCA c stent, percutaneous transluminal catheter angioplasty with stent insertion; ARF, acute renal failure; CRF, chronic renal failure; ESRD, end-stage renal disease; PAOD, peripheral artery obstructive disease; CVA, cerebrovascular accident; AMI, acute myocardial infarction; EF, ejection fraction; NYHA, New York Heart Association.

Serum cortisol concentrations were measured on a Bayer ACS-180 SE (Tarrytown, NY, USA) automated immunoassay analyzer using a competitive chemiluminescent assay (reference range from 07.00 to $09.00 \mathrm{~h}, 4.3-22.4 \mu \mathrm{g} / \mathrm{dl}$ ). In this assay, cortisol in the sample competes with acridinium ester-labeled cortisol for binding to a polyclonal rabbit anticortisol antibody complex coupled to a solid phase. After a 5-min incubation, the solid phase is separated magnetically, and chemiluminescence is generated by the addition of hydrogen peroxide in an alkaline environment. The cortisol concentration is inversely proportional to the light emitted and is interpolated from a stored master curve.

\section{Assessment of the Coagulation System}

Platelet count, prothrombin time, activated partial thrombin time, and plasma concentrations of D-dimer and fibrin degradation product were measured serially over time.

\section{Clinical Outcomes}

The duration of mechanical ventilatory support, length of ICU stay, postoperative blood loss, transfusion requirements, and length of hospitalization were recorded. We defined PIC as postoperative pulmonary complications, postoperative atrial fibrillation, and wound infections. Patients were discharged from hospital when they were apyrexial, in an overall satisfactory stable condition, and able to perform basic routine tasks.

\section{Postoperative Care}

All patients were managed in the ICU for 2 nights. Unless otherwise indicated, all patients underwent extubation on the following morning. Intravenous patient-controlled analgesia was administered for several postoperative days, followed by pain control with oral analgesics. Emphasis was placed on aggressive pulmonary care, early ambulation, and pain control to minimize postoperative pulmonary complications.

\section{Statistical Analysis}

All data are presented as mean \pm standard error of the mean. All statistical analyses were performed using the Statistical Package for Social Sciences Software version 12.0 (SPSS Inc, Chicago, IL, USA). Analysis of variance for repeated measurements was used to compare changes in time between the 2 patient groups. The significance levels of changes within groups were determined by the MannWhitney test. Survival curves were calculated by the Kaplan-Meier method and compared using the log-rank test. In all calculations, a p-value less than 0.05 was considered statistically significant.

\section{Results}

\section{Study Population}

The study population consisted of 100 patients (70 men and 30 women; mean age, $64.3 \pm 8.2$ years; range, 36-85 
Table 2 Postoperative Outcomes

\begin{tabular}{lccc}
\hline \hline & PIC group $(n=30)$ & Non-PIC group $(n=70)$ & $p$ value \\
\hline Operation time (min) & $255.7 \pm 50.3$ & $239.2 \pm 57.6$ & 0.248 \\
Distal anastomosis & $3.2 \pm 0.9$ & $3.3 \pm 0.7$ & 0.507 \\
CK-MB $($ ng/ml) & $19.8 \pm 34.2$ & $10.6 \pm 11.1$ & 0.189 \\
Postoperative bleeding/24h(ml) & $678.0 \pm 582.8$ & $628.1 \pm 369.4$ & 0.668 \\
Transfusion & $14(46.7)$ & $25(36.2)$ & 0.375 \\
Ventilator time $(h)$ & $33.5 \pm 45.3$ & $16.7 \pm 6.4$ & 0.003 \\
ICU stay $(h)$ & $127.3 \pm 284.9$ & $50.3 \pm 17.5$ & 0.027 \\
Hospital stay (days) & $18.1 \pm 23.3$ & $9.0 \pm 3.1$ & 0.002 \\
Vasopressin use & $11(36.7)$ & $27(39.1)$ & 0.827 \\
IABP use & $3(10.0)$ & $0(0)$ & 0.026 \\
\hline
\end{tabular}

CK-MB, myocardial-bound CK; ICU, intensive care unit; IABP, intraaortic balloon pump. Other abbreviation see in Table 1.

A

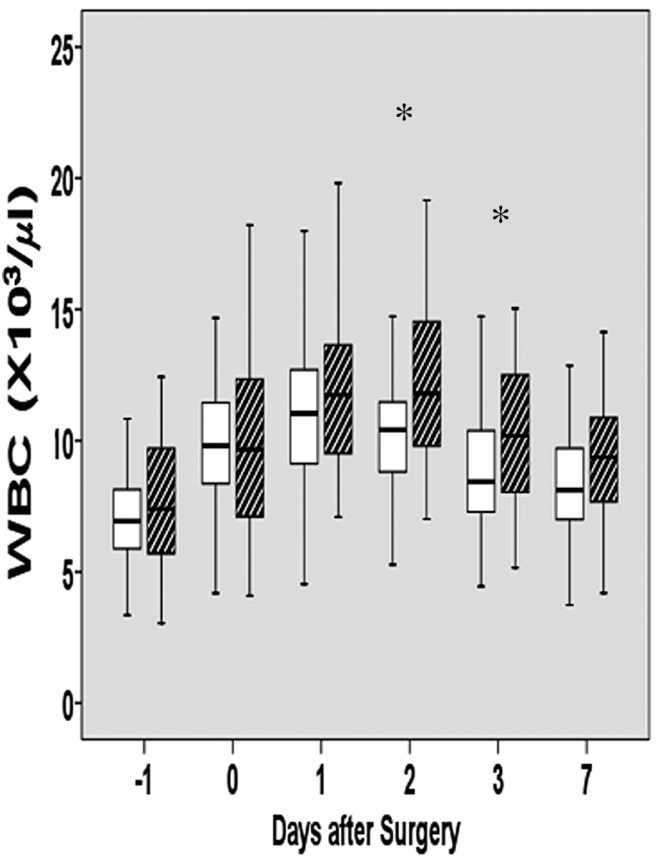

B

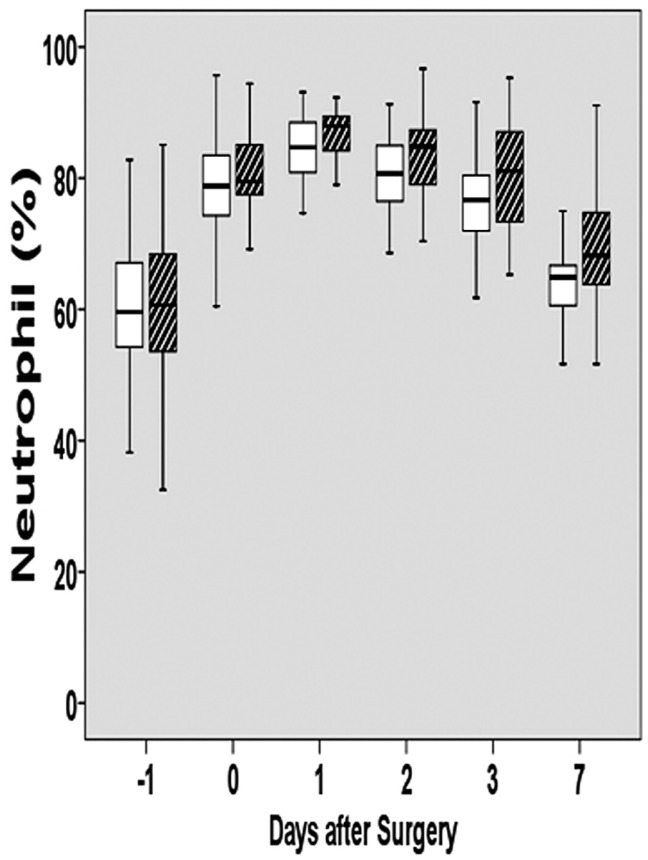

Fig 1. (A) Perioperative changes in white blood cell (WBC) counts according to development of postoperative inflammatory complications (PIC). (B) Perioperative changes in neutrophil percentage according to development of PIC (blank box, no PIC; shaded box, PIC; *p<0.05).

years) who underwent isolated primary OPCAB. Their preoperative ejection fraction was $55.8 \pm 0.5 \%$, and their standard and logistic Euroscores were $2.96 \pm 2.56$ and $3.45 \pm 6.91$, respectively. Sixteen patients $(16 \%)$ had already undergone percutaneous intraluminal catheter intervention. Seven patients were scored as New York Heart Association (NYHA) functional class I, 50 as NYHA class II, 32 as NYHA class III, and 11 as NYHA class IV. Eighty patients had triple vessel disease (Table 1). Preoperative clinical factors did not differ statistically between the PIC and non-PIC groups except age. The mean number of distal anastomosis was $3.2 \pm 0.7$ (Table 2).

\section{Perioperative Clinical Outcomes}

One patient died within 30 days after surgery ( $1 \%$ surgical mortality rate), who experienced postoperative atrial fibrillation, aspiration pneumonitis, perioperative myocardial infarction, and cardiac arrest on the second postoperative day. Although the patient was under percutaneous cardiopulmonary support system, he died of low cardiac output syndrome.
Multivariate analysis was not performed to assess death as a dependent variable, due to the small number of patients.

PIC occurred in 30 patients (postoperative pulmonary complications in 11 , postoperative atrial fibrillation in 17 , and wound infections in 4) at the median third postoperative day. Among the patients who experienced postoperative pulmonary complications, 6 experienced atelectasis, 2 experienced prolonged drainage of pleural effusion, 2 had pneumonia, and 1 had aspiration pneumonitis. All patients who experienced wound infections were categorized as superficial wound infection.

All patients were extubated between 6 and $20 \mathrm{~h}$ after arrival in the ICU; however, 2 patients required re-intubation and mechanical ventilatory support. One patient required a tracheostomy, and 3 patients $(3 \%)$ needed postoperative intra-aortic balloon pump insertion. The mean duration of mechanical ventilatory support was $16.7 \pm 6.4 \mathrm{~h}$ for patients without PIC and $33.5 \pm 16.7 \mathrm{~h}$ for patients with PIC $(\mathrm{p}=$ 0.003 ). Postoperative ICU stay was $50.3 \pm 17.5 \mathrm{~h}$ for patients without PIC and $127.3 \pm 285.0 \mathrm{~h}$ for patients with PIC 
A

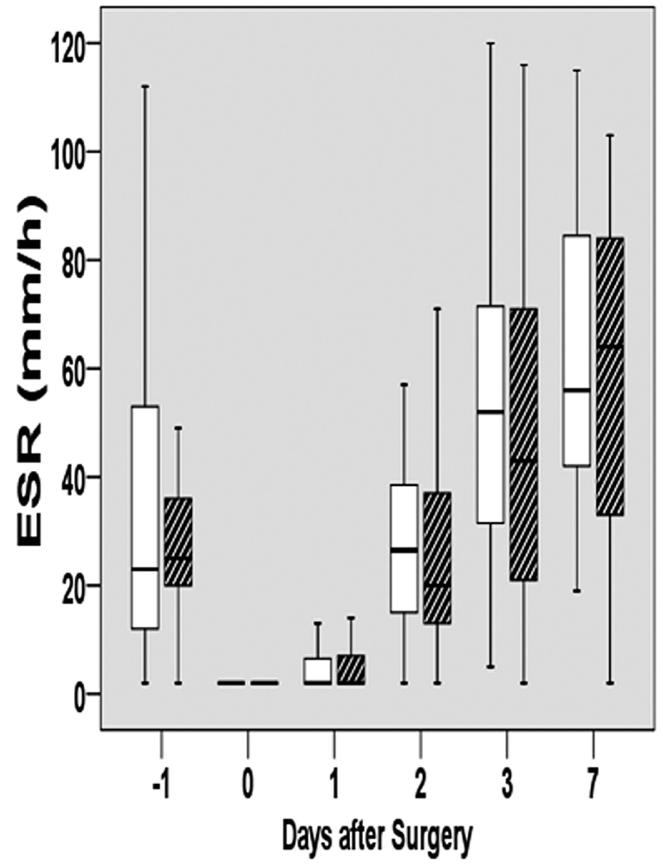

B

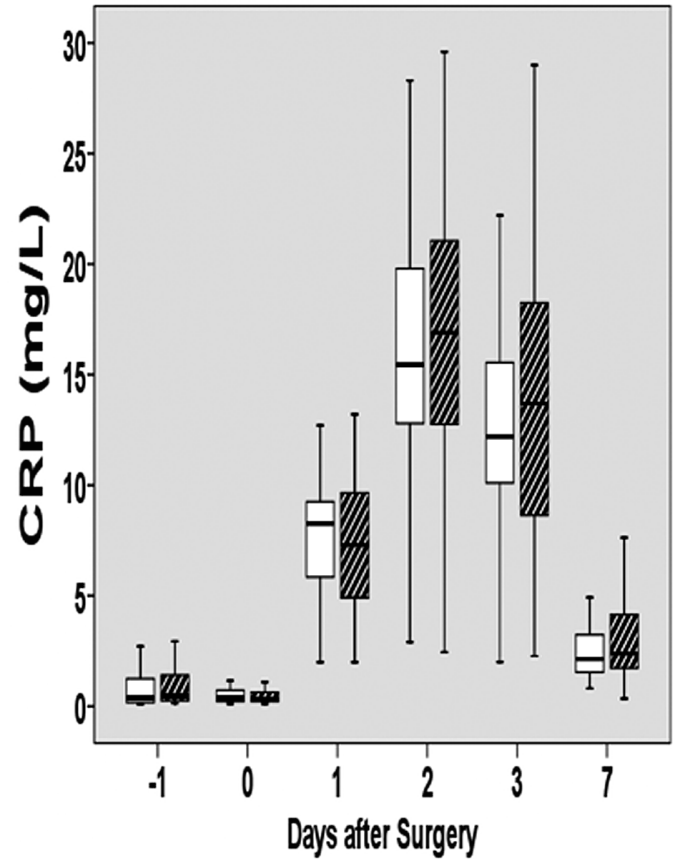

Fig 2. (A) Perioperative changes in erythrocyte sedimentation rate (ESR) according to development of postoperative inflammatory complications (PIC). (B) Perioperative changes in C-reactive protein (CRP) according to development of PIC (blank box, no PIC; shaded box, PIC).

A

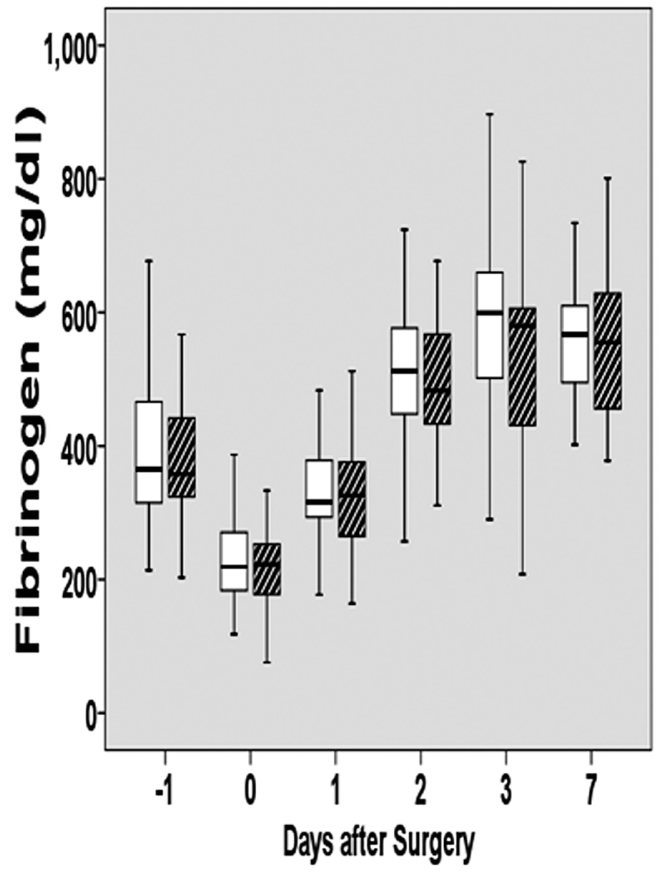

B

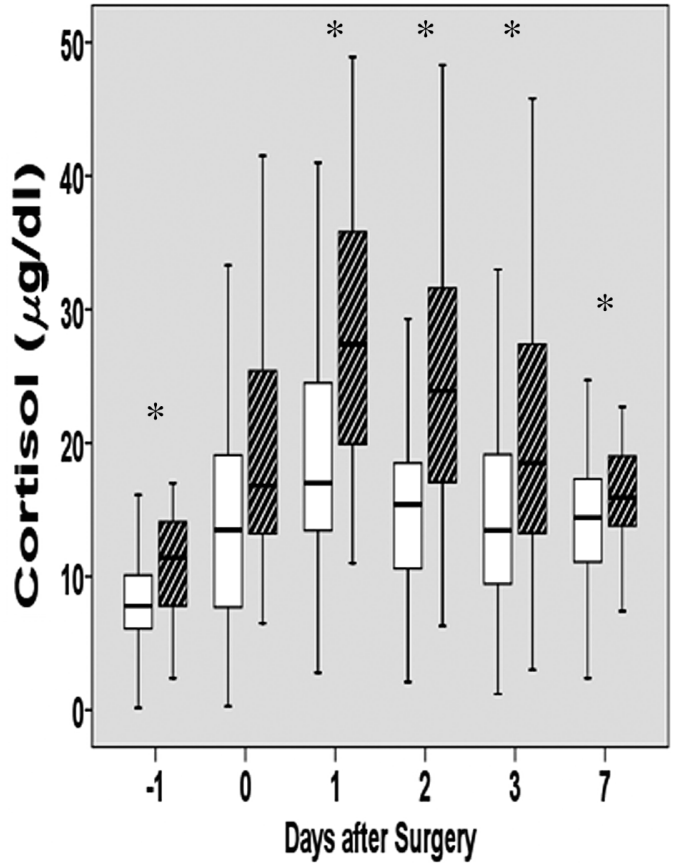

Fig 3. (A) Perioperative changes in fibrinogen according to development of postoperative inflammatory complications (PIC). (B) Perioperative changes in cortisol according to development of PIC (blank box, no PIC; shaded box, PIC; *p<0.05).

( $\mathrm{p}=0.027$ ). The length of hospital stay was $9.0 \pm 3.1$ days for patients without PIC and $18.1 \pm 23.3$ days for patients with PIC $(\mathrm{p}=0.002)($ Table 2$)$.

\section{Inflammatory Markers}

Leukocyte counts rose immediate after surgery in both groups, reaching a maximum on the first postoperative day in the non-PIC group and on the second postoperative day in the PIC group. Thereafter, leukocyte counts decreased gradually but remained above baseline in both groups on the seventh postoperative day. Leukocyte counts on the second $\left(12.4 \pm 3.1\right.$ vs $\left.10.3 \pm 2.7 \times 10^{3} / \mu \mathrm{l}, \mathrm{p}=0.003\right)$ and third $(10.3 \pm$ 
A

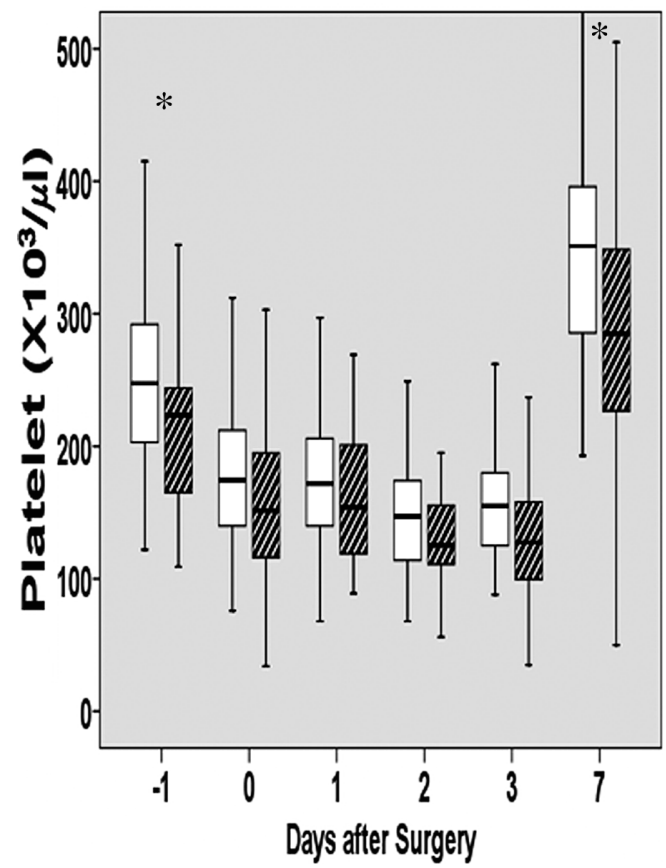

B

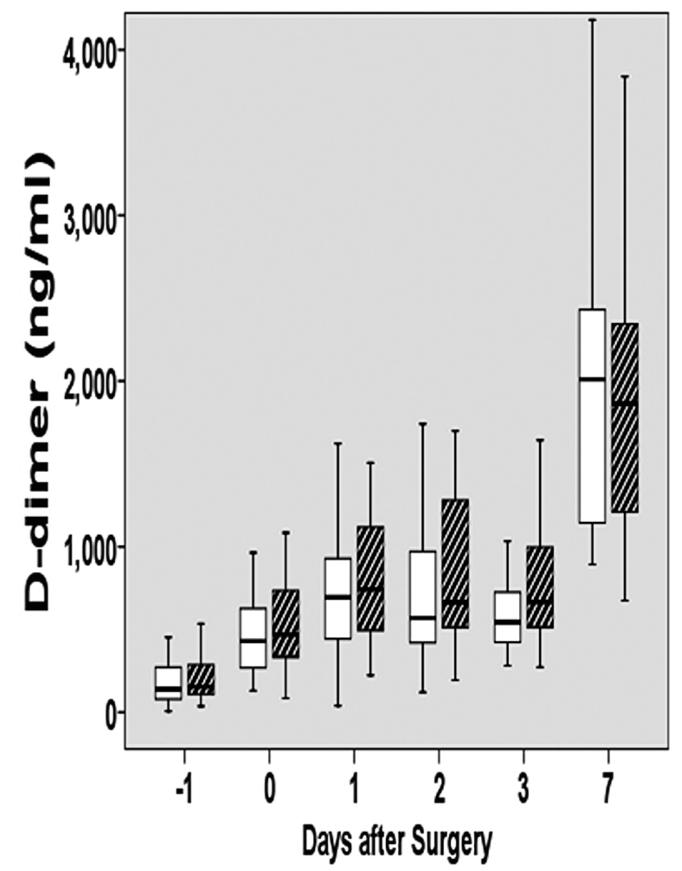

Fig 4. (A) Perioperative changes in platelet counts according to development of postoperative inflammatory complications (PIC). (B) Perioperative changes in D-dimer according to development of PIC (blank box, no PIC; shaded box, PIC; $* \mathrm{p}<0.05)$.

Table 3 Univariate and Multivariate Logistic Regression Analysis for Development of PIC After OPCAB

\begin{tabular}{|c|c|c|c|c|c|c|}
\hline & \multicolumn{3}{|c|}{ Univariate analysis } & \multicolumn{3}{|c|}{ Multivariate logistic regression } \\
\hline & $\begin{array}{l}\text { PIC group } \\
(n=30)\end{array}$ & $\begin{array}{c}\text { Non-PIC group } \\
\quad(n=70)\end{array}$ & $p$ value & $O R$ & $95 \% C I$ & $p$ value \\
\hline Age (year) & $66.8 \pm 7.2$ & $62.4 \pm 10.5$ & 0.038 & & & \\
\hline Preoperative day platelet $\left(10^{3} / \mu l\right)$ & $213.5 \pm 61.5$ & $254.7 \pm 86.6$ & 0.02 & & & \\
\hline Preoperative day cortisol $(\mu \mathrm{g} / \mathrm{dl})$ & $12.0 \pm 8.0$ & $8.6 \pm 4.3$ & 0.008 & 1.133 & $1.017-1.262$ & 0.024 \\
\hline $1^{\text {st }}$ postoperative day cortisol $(\mu \mathrm{g} / \mathrm{dl})$ & $30.3 \pm 15.3$ & $19.2 \pm 8.5$ & 0.001 & 1.084 & $1.031-1.140$ & 0.001 \\
\hline
\end{tabular}

OPCAB, off-pump coronary artery bypass surgery; OR, odds ratio; CI, confidence interval. Other abbreviation see in Table 1.

2.8 vs $\left.8.9 \pm 2.6 \times 10^{3} / \mu 1, \mathrm{p}=0.026\right)$ postoperative days were significantly higher in the PIC group (Fig 1A).

Neutrophil counts rose immediately after surgery in both groups, reaching a maximum on the first postoperative day and decreasing gradually thereafter, but remaining above baseline in both groups on day 7. Neutrophil counts did not differ between the 2 groups (Fig 1B).

After an initial decline immediate after surgery, ESR rose gradually in both groups until day 7. ESR levels, however, did not differ significantly between the 2 groups (Fig 2A).

CRP declined immediately after surgery, increased on the first postoperative day, reached a maximum level on the second postoperative day and then declined gradually, but remained above baseline in both groups on day 7. CRP concentrations did not differ between the 2 groups (Fig 2B).

Fibrinogen concentrations declined immediately after surgery, increased on the first postoperative day, reached a maximum level on the third postoperative day, and then decreased gradually but remained high on day 7 . Fibrinogen concentrations did not differ between the 2 groups (Fig 3A).

Cortisol concentration rose immediate after surgery in both groups, reaching a maximum on the first postoperative day and decreased gradually thereafter, but remained above baseline in both groups on day 7. Two-way analysis of variance for repeated measurements showed that the changes in cortisol concentrations were significant within each group over time and approached significance between the groups $(\mathrm{p}<0.05)$. Compared with the non-PIC group, cortisol concentrations in the PIC group were significantly higher preoperatively $(12.0 \pm 8.0$ vs $8.6 \pm 4.3 \mu \mathrm{g} / \mathrm{dl}, \mathrm{p}=0.008)$ and on postoperative days $1(30.3 \pm 15.3$ vs $19.2 \pm 8.5 \mu \mathrm{g} / \mathrm{dl}, \mathrm{p}=0.001)$, $2(24.2 \pm 10.5$ vs $15.4 \pm 7.3 \mu \mathrm{g} / \mathrm{dl}, \mathrm{p}=0.001), 3(22.3 \pm 14.2$ vs $14.3 \pm 7.1 \mu \mathrm{g} / \mathrm{dl}, \mathrm{p}=0.004)$ and $7(17.0 \pm 6.2$ vs $14.3 \pm 5.3 \mu \mathrm{g} / \mathrm{dl}$, $\mathrm{p}=0.042)($ Fig 3B).

\section{Coagulation Systems}

Platelet counts decreased gradually, starting immediately after surgery until day 3 , but recovered to baseline on day 7 . Preoperative platelet count was significantly lower in the PIC group than in the non-PIC group (213.5 \pm 61.5 vs $254.7 \pm$ $\left.86.6 \times 10^{3} / \mu 1, p=0.02\right)(\mathrm{Fig} 4 \mathrm{~A})$.

D-dimer concentrations rose gradually, starting immediately after surgery until day 7 . D-dimer concentrations did not differ significantly between the 2 groups (Fig 4B). 
A

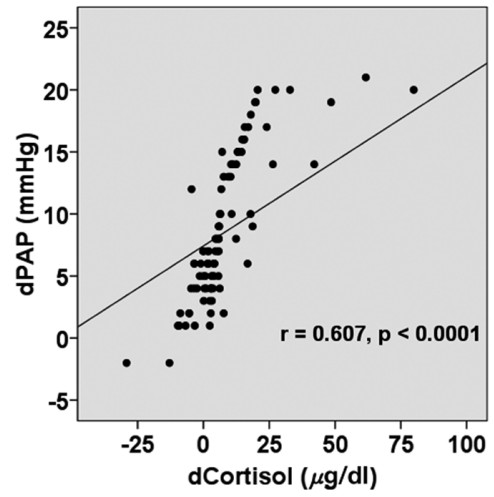

B

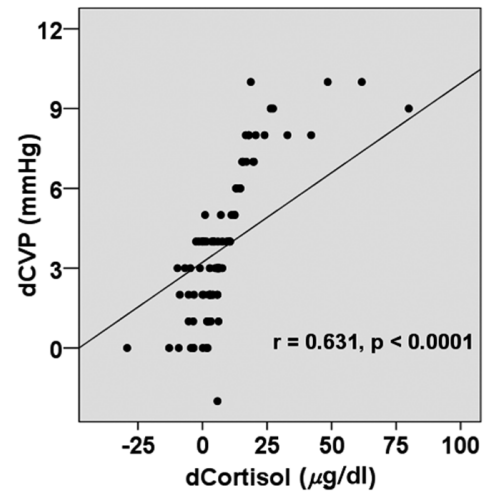

C

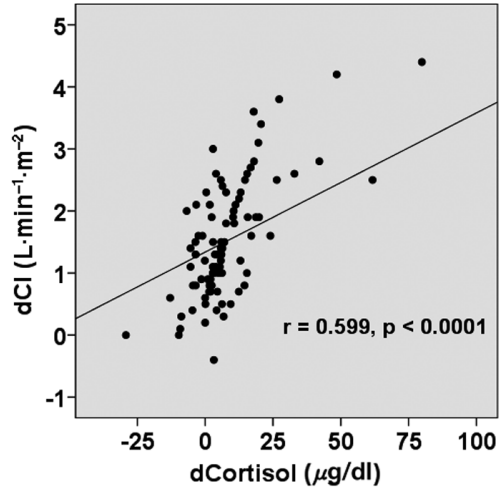

Fig 5. Relationship between intraoperative cortisol release and intraoperative hemodynamic changes. Intraoperative cortisol release was calculated as the difference between immediate postoperative and preoperative cortisol concentrations, and changes in hemodynamic data were calculated as the difference between each parameter during left circumflex artery anastomosis and just after induction of anesthesia. (A) Intraoperative cortisol release was correlated with intraoperative mean pulmonary artery pressure (PAP, $r=0.607, \mathrm{p}<0.0001$ ). (B) Intraoperative cortisol release was correlated with central venous pressure $(\mathrm{CVP}, \mathrm{r}=0.631, \mathrm{p}<0.0001)$. (C) Intraoperative cortisol release was negatively correlated with cardiac index $(\mathrm{CI}, \mathrm{r}=-0.599, \mathrm{p}<0.001)$.

\section{Risk Factors for PIC}

Since earlier prediction of PIC after OPCAB might be very important, we assessed risk factors before and immediately after surgery. Univariate analysis showed that age $(\mathrm{p}=$ $0.038)$, preoperative platelet count $(\mathrm{p}=0.02)$ and preoperative cortisol concentation $(\mathrm{p}=0.008)$, and day 1 postoperative cortisol concentration $(\mathrm{p}=0.001)$ were associated with development of PIC.

Multivariate logistic regression analysis showed that higher preoperative cortisol concentration $(12.0 \pm 8.0$ vs $8.6 \pm 4.3 \mu \mathrm{g} / \mathrm{dl}, \mathrm{p}=0.024)$, and higher cortisol concentration on postoperative day $1(30.3 \pm 15.3$ vs $19.2 \pm 8.5 \mu \mathrm{g} / \mathrm{dl}, \mathrm{p}=0.001)$ were significantly associated with the development of PIC (Table 3).

\section{Intraoperative Hemodynamic Changes}

We also assessed the relationship between intraoperative cortisol release and intraoperative hemodynamic changes, including mean arterial pressure, heart rate, central venous pressure, mean pulmonary artery pressure, cardiac index, and mixed venous $\mathrm{O}_{2}$ saturation. Intraoperative cortisol release was calculated as the difference between immediate postoperative and preoperative cortisol concenrations, and changes in hemodynamic variables were calculated as the difference between each parameter during left circumflex artery anastomosis and just after induction of anesthesia.

Intraoperative cortisol release was well correlated with intraoperative mean pulmonary artery pressure $(\mathrm{r}=0.628, \mathrm{p}<$ $0.0001)$, central venous pressure $(r=0.633, p<0.0001)$, and cardiac index $(\mathrm{r}=-0.516, \mathrm{p}=0.001)$ (Fig 5). Also, we compared the intraoperative cortisol release between the 2 groups $(15.1 \pm 14.6 \mu \mathrm{g} / \mathrm{dl}$ in the PIC group, and $7.7 \pm 14.1 \mu \mathrm{g} / \mathrm{dl}$ in the non-PIC group, $\mathrm{p}=0.032$ ).

\section{Discussion}

On-pump coronary artery bypass surgery (ONCAB) has risks of mortality $(2-5 \%)$, stroke (2\%), transfusions (30$90 \%$ ), atrial fibrillation (30\%), and neurocognitive dysfunction (50-75\%) ${ }^{17-20}$ Comparisons of OPCAB and ONCAB have shown that OPCAB is associated with improvements in short-term outcomes, including atrial fibrillation, blood transfusion, and length of hospital stay in patients not selected for risk ${ }^{21}$ Despite these advantages, many PIC can occur after OPCAB, and these are associated with prolonged hospital stay and eventually surgical mortality. Thus, accurate prediction of PIC in patients with coronary artery obstructive disease is very important. Patients with coronary artery disease who undergo evaluation for OPCAB usually have a history of diabetes, hypertension, smoking, and/or chronic obstructive pulmonary disease with impaired lung function, putting them at increased risk for development of PIC. Therefore, in addition to assessing the clinical status of coronary lesions, physiological assessment of these patients is very important. However, little is known about the factors associated with overall morbidity and mortality after OPCAB.

We have shown here that increased cortisol concentrations preoperatively and on the first postoperative day are independent predictors for development of PIC after OPCAB. Cortisol is an inflammatory marker and acute stress hormone that is synthesized by the adrenal gland and released in large amounts into the circulation, primarily in response to interleukin-6 stimulation, during systemic inflammation. Elevated serum cortisol can affect coagulability, blood viscosity and rheology, platelet aggregation, and endothelial function, all of which might induce microthrombosis in the collateral capillaries and ischemic changes, and make patients vulnerable to ischemia, inflammation, and infection, especially after surgery. Therefore, measurement of serum cortisol concentrations might provide a non-invasive method of identifying ongoing inflammation and tissue ischemia.

Despite avoiding $\mathrm{CPB}$, OPCAB is associated with decreases in $\mathrm{PaO}_{2}$, pulmonary compliances, and pulmonary function similar to on-pump CABG, which might lead to delayed extubation and necessitate strategies to minimize postoperative pulmonary impairments 22,23 In addition, temporary interruption of the coronary blood flow for bloodless anastomotic conditions might cause various degrees of myocardial damage. Although the period of 1 target vessel occlusion is usually approximately $15 \mathrm{~min}$, multiple grafts might be associated with cumulative ischemia-reperfusion myocardial injury? 24,25 
Compared with the controlled systemic flow conditions of $\mathrm{CPB}$, cardiac manipulation during $\mathrm{OPCAB}$ to expose target coronary arteries can lead to significant hemodynamic impairment, with transient drops in cardiac output, despite relative preservation of the mean arterial pressure. Hemodynamic deterioration is primarily caused by right ventricular dysfunction, resulting from compression of the right heart chambers against the surrounding fibrous pericardium and pleura ${ }^{26}$ These hemodynamic changes are more pronounced when extensive cardiac manipulation is required to expose a target vessel on the posterolateral aspect of the heart, and are generally reversible once the heart is replaced in its normal position. Thus, in terms of stress hormone response, the benefits conferred by avoiding CPB might be negated by the cumulative hemodynamic stress of OPCAB surgery.

We found significant correlations between intraoperative cortisol release and intraoperative hemodynamic changes. Furthermore, we tested if intraoperative cortisol release could be a significant risk factor for development of PIC. Intraoperative cortisol release was $15.1 \pm 12.6 \mu \mathrm{g} / \mathrm{dl}$ in the PIC group, and $7.7 \pm 14.1 \mu \mathrm{g} / \mathrm{dl}$ in the non-PIC group $(\mathrm{p}=0.032)$. As a result, summation of intraoperative hemodynamic changes affected intraoperative cortisol release, and then it could affect the development of PIC. Because intraoperative hemodynamics during OPCAB are controlled by the cardiovascular surgeon and by experienced cardiac anesthesiologists, close cooperation between them during OPCAB can minimize intraoperative hemodynamic changes, intraoperative cortisol release, and PIC.

Preoperative serum cortisol is a surrogate measurement of the level of preoperative stress and inflammatory response. In contrast, serum cortisol concentration on the first postoperative day is a summation of the cumulative effect of preoperative cortisol, intraoperative cortisol release, and cortisol release during the first $12 \mathrm{~h}$ postoperatively.

We hypothesized that perioperative serial measurements would provide a more accurate picture of the cumulative effect of surgery on the hormonal milieu, enabling a valid comparison between the PIC and non-PIC group. Unexpectedly, however, we found that immediate postoperative serum cortisol concentration did not differ between the 2 groups. Serum cortisol concentration immediately after surgery was thought difficult to interpret in the context of hemodilution during OPCAB. This issue has been controversial, with most authors suggesting that no correction should be made for hemodilution, as the concentration of a hormone in a target organ is directly affected by its concentration in the serum rather than the total amount in the intravascular fluid. However, we cannot assess the effect of hemodilution. This confounding factor is less relevant beginning on postoperative day 1 , when the body has begun to compensate by redistributing the excess volume between its fluid compartments. In addition, the serum concentration of cortisol undergoes diurnal variation, with the highest levels present in the early morning, and the lowest levels present around midnight, $3-5 \mathrm{~h}$ after the onset of sleep. We measured immediate postoperative cortisol in arterial blood at around $14.00-16.00 \mathrm{~h}$, at which time cortisol level was lower than at $07.00-09.00 \mathrm{~h}$. Thus, we could not correct the immediate postoperative cortisol concentration because of the hemodilution effect and diurnal variation.

In conclusion, we have shown here that patients with PIC after OPCAB have significantly increased cortisol concentrations, preoperatively and on the first postoperative day. We also found that intraoperative cortisol release was significantly correlated with intraoperative hemodynamic changes. Our findings suggest that the neurohormonal environment and inflammatory response during and after beating-heart surgery should be further explored.

\section{Acknowledgement}

The authors are deeply grateful to Eun-A Kang, RN, and Hee-Jung Lee, $R N$ for their valuable contributions in collecting the data used in this article.

\section{References}

1. Kirklin JK, Westaby S, Blackstone EH, Kirklin JW, Chenoweth DE, Pacifico AD. Complement and the damaging effects of cardiopulmonary bypass. J Thorac Cardiovasc Surg 1983; 86: 845-857.

2. Moat NE, Shore DF, Evans TW. Organ dysfunction and cardiopulmonary bypass: The role of complement and complement regulatory proteins. Eur J Cardiothorac Surg 1993; 7: 563-573.

3. Frering B, Philip I, Dehoux M, Rolland C, Langlois JM, Desmonts JM. Circulating cytokines in patients undergoing normothermic cardiopulmonary bypass. J Thorac Cardiovasc Surg 1994; 108: 636641.

4. Duke T, South M, Stewart A. Altered activation of the L-arginine nitric oxide pathway during and after cardiopulmonary bypass. Perfusion 1997; 12: 405-410.

5. Cavarocchi NC, England MD, Schaff HV, Russo P, Orszulak TA, Schnell WA Jr, et al. Oxygen free radical generation during cardiopulmonary bypass: Correlation with complement activation. Circulation 1986; 74(Suppl): III-130-III-133.

6. Iskesen I, Saribulbul O, Cerrahoglu M, Var A, Nazli Y, Sirin H. Trimetazidine reduces oxidative stress in cardiac surgery. Circ $J$ 2006; 70: 1169-1173

7. Hill GE, Alonso A, Spurzem JR, Stammers AH, Robbins RA. Aprotinin and methyprednisolone equally blunt cardiopulmonary bypass-induced inflammation in humans. J Thorac Cardiovasc Surg 1995; 110: $1658-1662$.

8. Hill GE, Pohorecki R, Alonso A, Rennard SI, Robbins RA. Aprotinin reduces interleukin- 8 production and lung neutrophil accumulation after cardiopulmonary bypass. Anesth Analg 1996; 83: 696-700.

9. Karaca P, Konuralp C, Enc Y, Suzer A, Sokullu O, Ayoglu U, et al. Cardioprotective effect of aprotinin on myocardial ischemia/reperfusion injury during cardiopulmonary bypass. Circ J 2006; 70: 1432 1436.

10. Gu YJ, van Oeveren W, Akkerman C, Boonstra PW, Huyzen RJ, Wildervuur CRH. Heparin-coated circuits reduce the inflammatory response to cardiopulmonary bypass. Ann Thorac Surg 1993; 55: 917-922.

11. Millar AB, Armstrong L, van der Linden J, Moat N, Ekroth R, Westwick J, et al. Cytokine production and hemofiltration in children undergoing cardiopulmonary bypass. Ann Thorac Surg 1993; 56: 1499-1502.

12. Buffolo E, de Andrade CS, Branco JNR, Teles CA, Aguiar LF, Gomes WJ. Coronary artery bypass grafting without cardiopulmonary bypass. Ann Thorac Surg 1996; 61: 63-66.

13. Gu YJ, Mariani MA, van Oeveren W, Grandjean JG, Boonstra P. Reduction of the inflammatory response in patients undergoing minimally invasive coronary artery bypass grafting. Ann Thorac Surg 1998; 65: $420-424$.

14. Fransen E, Maessen J, Dentener M, Senden N, Geskes G, Buurman W. Systemic inflammation present in patients undergoing CABG without extracorporeal circulation. Chest 1998; 113: 1290-1295.

15. Lee HS, Lee JM, Kim MS, Kim HY, Hwangbo B, Zo JI. Low-dose steroid therapy at an early phase of postoperative acute respiratory distress syndrome. Ann Thorac Surg 2005; 79: 405-410.

16. Song SW, Lee HS, Kim MS, Lee JM, Kim JH, Nam BH, et al. Preoperative serum fibrinogen level predicts postoperative pulmonary complications after lung cancer resection. Ann Thorac Surg 2006; 81: $1974-1981$

17. SoS Investigators. Coronary artery bypass surgery versus percutaneous coronary intervention with stent implantation in patients with multivessel coronary artery disease (the Stent or Surgery trial): A randomised controlled trial. Lancet 2002; 360: 965-970.

18. Stover EP, Siegel LC, Parks R, Levin J, Body SC, Maddi R, et al. Variability in transfusion practice for coronary artery bypass surgery persists despite national consensus guidelines: A 24-institution study. Institutions of the Multicenter Study of Perioperative Ischemia Research Group. Anesthesiology 1998; 88: 327-333.

19. Stamou SC, Hill PC, Dangas G, Pfister AJ, Boyce SW, Dullum MK, 
et al. Stroke after coronary artery bypass: Incidence, predictors, and clinical outcome. Stroke 2001; 32: 1508-1513.

20. Mathew JP, Parks R, Savino JS, Friedman AS, Koch C, Mangano DT, et al. Atrial fibrillation following coronary artery bypass graft surgery: Predictors, outcomes, and resource utilization. MultiCenter Study of Perioperative Ischemia Research Group. JAMA 1996; 276: 300-306.

21. Cheng DC, Bainbridge D, Martin JE, Novick RJ; Evidence-Based Perioperative Clinical Outcomes Research Group. Does off-pump coronary artery bypass reduce mortality, morbidity, and resource utilization when compared with conventional coronary artery bypass? A meta-analysis of randomized trials. Anesthesiology 2005; 102: $188-203$.

22. Montes FR, Maldonado JD, Paez S, Ariza F. Off-pump versus onpump coronary artery bypass surgery and postoperative pulmonary dysfunction. J Cardiothorac Vasc Anesth 2004; 18: 698-703.
23. Kochamba GS, Yun KL, Pfeffer TA, Sintek CF, Khonsari S. Pulmonary abnormalities after coronary arterial bypass grafting operation: Cardiopulmonary bypass versus mechanical stabilization. Ann Thorac Surg 2000; 69: 1466-1470.

24. Kwak YL. Reduction of ischemia during off-pump coronary artery bypass graft surgery. J Cardiothorac Vasc Anesth 2005; 19: $667-$ 677.

25. Puskas JD, Vinten-Johansen J, Muraki S, Guyton R. Myocardial protection for off-pump coronary artery bypass surgery. Semin Thorac Cardiovasc Surg 2001; 13: 82-88.

26. Grundeman PF, Borst C, Verlaan CW, Meijburg H, Moues CM, Jansen EW. Exposure of circumflex branches in the tilted, beating porcine heart: Echocardiographic evidence of right ventricular deformation and the effect of right or left heart bypass. J Thorac Cardiovasc Surg 1999; 118: 316-323. 